\title{
The Myths about Forecasting, Business Cycles and Time Series, Which Prevent Economists to Forecast: With an Application to Shipping Industry
}

\author{
Alexandros M. Goulielmos ${ }^{1,2}$ \\ ${ }^{1}$ Marine Economics, University of Piraeus, Piraeus, Greece \\ ${ }^{2}$ Department of Maritime Studies, Shipping Division of Business College of Athens, Athens, Greece \\ Email: ag@unipi.gr, am.goulielmos@hotmail.com, agoulielmos@bca.edu.gr
}

How to cite this paper: Goulielmos, A.M. (2017) The Myths about Forecasting, Business Cycles and Time Series, Which Prevent Economists to Forecast: With an Application to Shipping Industry. Modern Economy, 8, 1455-1477.

https://doi.org/10.4236/me.2017.812097

Received: October 13, 2017

Accepted: September 5, 2017

Published: September 8, 2017

Copyright $\odot 2017$ by author and Scientific Research Publishing Inc. This work is licensed under the Creative Commons Attribution International License (CC BY 4.0).

http://creativecommons.org/licenses/by/4.0/ (c) (i) Open Access

\begin{abstract}
People did not forgive economists for not forecasting the two great depressions. Especially the second one in end-2008-which followed the 1929-1933 "Great Depression" (starting on 29/10/1929: the "Black Tuesday"). Keynes in 1936, wrote a book on "economics of depression", and showed the way how full employment-through marginal efficiency of capital-can be achieved. He was bypassed by: his death (1946) and his disciples' efforts to "model economic growth" (Harrod, 1939 and Domar, 1946). Progress in capitalistic economies cannot be achieved...without Keynes' animal spirits. The "wrong beliefs" of my fellow economists, which we called them "myths" for sensation, were showed: "myths" about business cycles, time series and forecasting. Though in the long run we are all dead, economic history...remembers. The "trade cycle" theory, which eventually became "business cycle", was in scientific focus from 1907 to 1941, and then disappeared. Cycles made the life of shipowners difficult since 1741: one cycle every 10 years! Ships, however, are assets of long life, living 3.2 times the typical shipping cycle-and we said-for the first time-that the "duration of a shipping slump is related to the durability of ships"...Moreover: cycles are influenced by the state of technology; this stated also for the first time; cycles do not go up $\mathrm{x}$ years and exactly $\mathrm{x}$ years down. Maritime economists by this made shipowners and shippers happy: but, as shown, most freight rate's peaks lased $1-2$ years and troughs lasted up to 12 years (1947-2016)...Cycles, early in history, attracted the attention ${ }^{1}$ of many writers (we counted 449 writers, including Keynes with 12 papers). Most believe that "trade cycle theory" started with Jevons (in 1909), but as Mandelbrot
\end{abstract}

${ }^{1} \mathrm{AEA}$, Readings in Business Cycle theory (1950) [1]. 
and Hudson (2004; 2008 preface [1]) wrote, Bible described a cycle of 7 years up and down; cycles cannot be predicted and their trends and turning points cannot be found. We have showed that these are not true. Myths concerned also time series like: time series have no memory; they move at the square root of time $(\mathrm{H}=1 / 2)$-as proved by Einstein (1905) - and they are best represented by "bell" curve. Hurst (1951) showed that Einstein's case is a special one, and time series can move faster or slower than that. More important was that if $\mathrm{H}>0.50 \leq 1$, time series have to produce cycles: this is an important finding. The general formula shown here includes coefficients: alpha (fat tails; risk), beta (skewness), gamma (scale) and delta (location). Alpha indicates the height of a distribution and the longevity of its tails-indicating what the real risk is, when a variable falls beyond $3 \sigma$ - "Dow" fell 22s away on Black Monday 1987, and the freight rates index $\sim 10 \sigma$ in end-2008 meltdown.... The myths about forecasting are connected with the fact that econometricians prefer to predict nonlinear time series using linear tools (e.g. $\mathrm{GARCH}^{2}$ ). We did the opposite: we forecast the nonlinear (shipping) time series index of dry cargoes 1741-2015 (7 years inside the sample and 5 years outside it) testing 5 nonlinear methods and eventually selecting the best one (i.e. the "Kernel density estimation"). The deviations obtained were from $2 \%$ to $10 \%$ (yearly) from actual-we also indicated a falling trend. In fact there is no turning point up in shipping dry cargo market...by 2020 ..

\section{Keywords}

Keynes's Theory of Depression, Economic “Mythology”, The Truth About Business Cycles-Time Series and Forecasting, Shipping, Nonlinear Time Series Analysis, Forecasting Turning Points

\section{Introduction}

I was for a long time worried about the reputation that maritime forecasters have accumulated from shipowners ${ }^{3}$, and members of the Academe...Stopford (2009) [3] argued that a variety of different people-very important for us-are in need of forecasting: i.e. in all investment decisions, in choosing a charter, in lending money by bankers; in selling ships by shipyards, priced hundred thousands of \$; in promoting ship equipment by engineering companies; in calculating risk, by rating agencies; for the development of additional facilities by portscosting millions of dollars.

However, despite the importance of forecasting, Stopford (2009) [3]) wrote:

${ }^{2}$ The Generalized $\left(^{*}\right)$ Auto-Regressive Conditional $\left({ }^{*}\right)$ Heteroscedasticity model refers to a set of statistical tools; data's $\left(^{* *}\right)$ variability changes with time, controlled by data's past behavior; $\left(^{*}\right)$ generalized means compared with ARCH 1982. It starts with a conventional Brownian motion of price variation-as volatility clusters, due to dependence- and when volatility jumps, the model plugs in new parameters to make the bell curve grow, and vice versa. What makes the bell curve to vibrate (?) this is a good question (Mandelbrot and Hudson, 2004, p. 222, 291 [2]), not answered.

${ }^{3}$ A successful shipowner-Mr. Thanassis Martinos-forecast 4 freight markets in 2016! 
0 "to be realistic, maritime forecasting has a poor reputation, and the sense that forecasts are usually...wrong, is widely held in (maritime) industry". In addition, the Planning director of UK Shell confirmed ${ }^{4}$ Stopford's opinion about forecasting oil industry in the 1960s and in early 1970s. Surely, these were turbulent years in end 1973+, and even Onassis forecast them wrong!

\section{Scope and Structure of Paper}

This paper aims at stating out clearly the myths believed by general economists and shipping ones, as far as forecasting, business cycles and time series are concerned; also, restoring the truth and contributing to an improvement of the effectiveness of economists to forecast. It is high time for economists to restore their bad reputation about accurate forecasts.

The paper is organized as follows: Next is a literature review; then, comments on business and shipping cycles are made. Next, we reveal the myths that exist about business cycles, time series, finance and shipping forecasting. Then, we provide a forecasting example of the "dry cargo freight rate index" since 1741 for 7 years (2009-2015) inside the sample and 5 years (2016-2020) outside it, using a nonlinear method (the "Kernel density estimation"). Finally, we conclude.

\section{Literature Review}

\subsection{On Shipping Forecasting}

Seland [5] argued that ancient Greeks used oracles ${ }^{5}$; Romans had also their own; medieval times had their fortune-tellers. Today, we have economists. The esteem in which economists are held is rather varied: often, fairly high, by those who read prophesies, and generally rather low, by those who remember them...He advised his students to forecast for 10 years-at least-ahead...then they will have the option to say: "As I wrote ten years ago..." or remain silent...

Hearth [6] argued that the overall forecast of demand for oil was right: a 7\% 9\% compound increase between 1965 and 1980. Forecasters failed in anticipating 'economies of scale'! Tankers above 100,000 dwt forecast to be $4.5 \mathrm{~m}$ dwt by 1980 -since 1965-but at May $197051.2 \mathrm{~m}$ dwt already were on order and construction, of 150,000 dwt size and over each... Onassis by instinct believed in both - an increasing demand and economies of scale.

Stopford [7] reviewed 3 main segments of shipping for their likely development by 2003. He said that the Greek (he was Latin) poet Horace (65-68 B.C.) wrote: "adversity reveals the genius, prosperity conceals them". Recessions and shipping go together, Stopford wrote. The year 2000 was as good as 1973 (rather 1974). The "Clarksea index" peaked at $\$ 25,575 /$ day in end-2000. The bulk carrier market paid a heavy price for its investment boom in 1999; so the market re${ }^{4}$ Mentioned by Stopford (2009 [3] p. 695); Beck (1983) [4].

${ }^{5}$ They used to deliver oracles with double meaning...E.g. one man going to war asked if he will die there. The oracle said: "you go, you return (,) not (,) in war die". The meaning is different depending on where you put a comma: (1) "you go, you return not, in war die" and (2) "you go, you return, not in war die". 
mained weak and moved into recession; the "order book" forecast to wind down over 2002, and bulk trade to decline. Was he right? No, the 2000 dry cargo index (Stopford, 2009 [3]; and Figure 1 here) showed for 2000164 units compared with 135 in 1973 (and 168 in 1974), 155 in 2002 and 253 in 2003. Market improved due to "China effect".

Lorange (2009) [8] argued that forecasting comes first from consulting firms on forecasting (like Marsoft; Jefferies \& Co Inc.; Maritime strategies int.-MSI; China ship economy research center; Drewry and others); research units within traditional shipbrokers (like Clarkson, Platou, Fearnleys); specialized ship consulting firms (like Carl Bro, Vik \& Sanbdvik, Skipsteknisk) after ship designs. He admitted: good forecasting is the key, and its role is important.

Eslami et al. [9] argued that their model-a hybrid one based on "Artificial Neural Network" - ANN, and an "adaptive generic algorithm" — was superior of regression, moving averages and pre-existing ANN studies. The RMSE ("root mean squared error") was for their model 11.2WS units (worldscale ${ }^{7}$ ) vis-à-vis regression of 21.6WS and moving averages of 17.5WS and other ANN studies from 14.6 to 15.8WS (1983-2003).

Looking at their predictions, (their Figure 6), over 30 or so months, however, the difference between actual and their model was 30WS units at the $\sim 27$ th or so month, while regression model was worse by $42 \mathrm{WS}$, but moving averages were

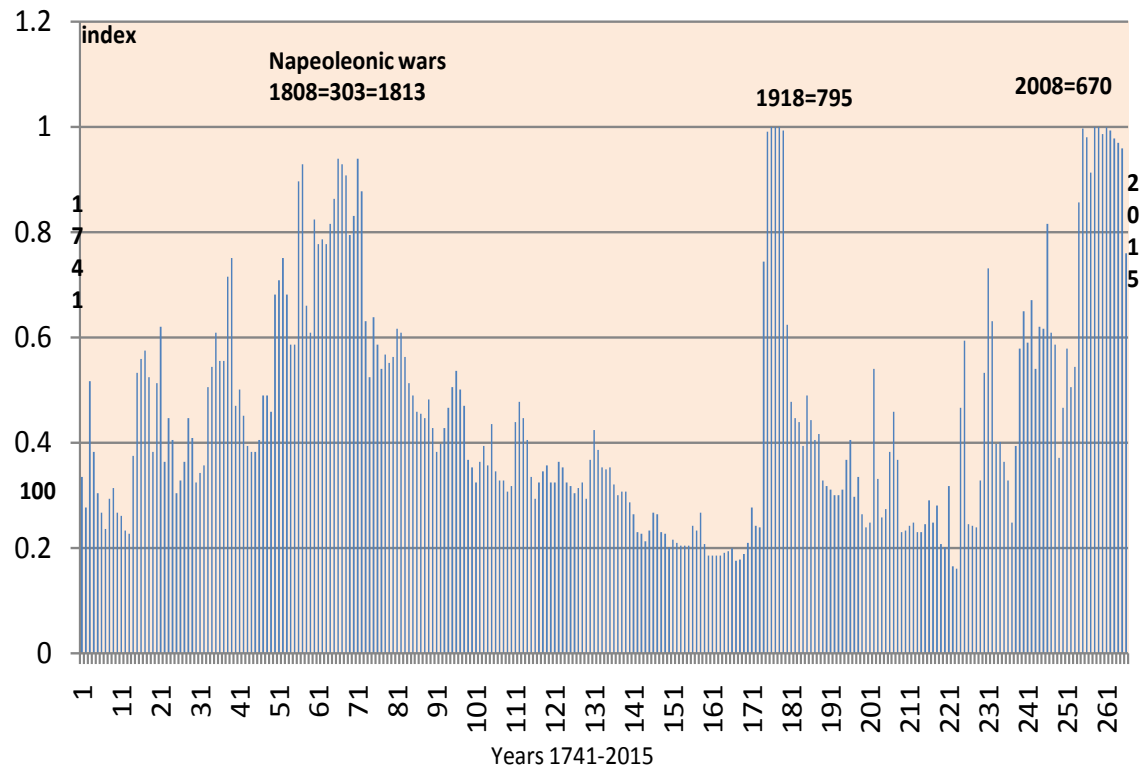

Figure 1. The freight rates index of dry cargo 1741-2015 (1741 = $100=1947)$ Data: from Stopford (2009 [3]), 1741 till 2007; from Clarkson's staff: 2008-2015; data for 1939-1946 (8 years) are missing.

${ }^{6} \mathrm{His}$ book in 2009 [8] is very interesting — though most empirical—as he used to be a shipowner and at the same time a Professor! He sold his shipping company in 2007, just before the meltdown...

${ }^{7}$ Worldscale $=\mathrm{a}$ tanker index which shows a standard revenue under certain prerequisites so that tanker owners to know what they get comparing with it; WS $=100=\$ 17.5$ per ton of oil (Jubail to Rotterdam). If owner gets WS $=50$, then he/she knows that he gets $\$ 8.75$ and $\$ 2.16 \mathrm{~m}$ instead of $\$ 4.375 \mathrm{~m}$ for the voyage. 
closer, by 20WS...To understand what 1WS means, we may say that 50WS means for a charterer to pay $\$ 8.65$ per ton of oil from Jubail to Rotterdam (authors used Ras Tanura ${ }^{8}$ to Rotterdam); in other words, a tanker of 250,000 dwt would expect to earn $\$ 4.375 \mathrm{~m}$ per voyage according to authors' forecast $(\sim 100 \mathrm{WS})$ and in fact she will get 30\% (30WS) less...A prediction model is not enough to be better than others, but also closer to reality to be useful to shipowners. This is another maritime forecasting failure.

\subsection{On Economic Forecasting}

Makridakis [10] argued that many people view forecasting as a crystal-ball attempt with little, or no, scientific or rational basis. Such a view was reinforced by prominent errors in forecasting events that did not materialize-like the forthcoming widespread use of nuclear energy and the appearance and impact of computers and information revolution. He suggested the meta-forecasting, based on rational principles arriving at future predictions scientifically sound -using feedback and learning.

Faggini and Parziale (2012) [11] stated their dissatisfaction for the inability of economics to foresee and proposed to resort to "Chaos Theory".

Weatherall (2013) [12]) doubted the idea that markets are efficient (p. 158)! This ("efficient market hypothesis" stream economic theory, representing one of the 3 sacred cows of modern economics. Mandelbrot and Hudson [2] argued $^{11}$ that EMH holds in an ideal market in which "all relevant information is already priced into a security (today)". Weatherall (2013) [12] argued that "wild randomness ${ }^{12 "}$ can be a sign of underlying...chaos... and there is often enough structure to make useful predictions...He left us a hope for predict-ability.

Buchanan (2013) [13] argued that economists, almost all, have virtually ig${ }^{8}$ Jubail like Ras Tanura are cities of Saudi Arabia on the east on Persian Gulf coast about 60 kilometers apart. Jubail is closer to Rotterdam.

${ }^{9}$ This deals with a deterministic, nonlinear, dynamic system, which can produce random-looking results. This must have a fractal (non-integer) dimension and exhibit sensitive dependence on starting conditions.

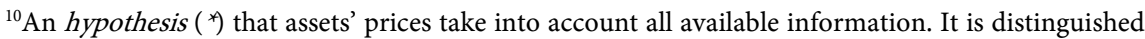
in 3 forms: weak, where the history of share prices cannot help to achieve excess returns; semi-strong, where public information does not help too.... and strong-form, where private information does not help too. Is it possible to know "who is buying what"? And what about the "Fidelity's Magellan Fund" in 1989 of Peter Lynch? Can one beat the market? $\left.{ }^{*}\right)$ term from Greek language meaning "assumption".

${ }^{11}$ This was the title given by Eugene F. Fama-a doctoral student of Mandelbrot at the University of Chicago. This is a broader variant of French Bachelier's (in 1900) thinking (Mandelbrot and Hudson, 2004, p. 11 [2]).

${ }^{12}$ Mandelbrot and Hudson [2] argued that as we have 3 states of matter-solid, liquid, and gas- so we have 3 random states-mild (bell curve), slow and wild-for markets. These states arise from "Fractal Geometry" ${ }^{*}$ ) (from his abstract to scientific reader, p. v). The conventional financial theory believes that the variation of prices can be modeled by random processes following the simplest "mild" pattern, as if each uptick or downtick is determined by the toss of a coin. But real prices "misbehave" (ibid). $\left(^{*}\right)$ Mandelbrot discovered 35 years ago (in 1982) the "geometry of nature", and certain of the mathematics of God. These are fractal...i.e. use non integer numbers... 
nored the most profound scientific discoveries of the past few decades-chaos theory-where the ongoing fluctuations in economic and financial systems are quite normal. The automatic efficiency of the "invisible hand" of Adam Smith is a chimeric bygone dream. Buchanan [13] (in jacket) argued that a smarter economics accepts that markets act much like the weather...while centuries of classical financial thought trained us to understand "the market" as a system that always returns to equilibrium ${ }^{13}$.

Wolf $^{14}$ (2014) [14] argued that he personally lacked the imagination to anticipate (p. xvi); he was guilty of working with a mental model of the economy that did not allow him to foresee the crisis in the world's most advanced economies (italics added). The crisis was the outcome of...a "rational carelessness" [14], he wrote...

In summary, we believe that the idea of the "invisible hand", which no doubt is present in the celestial system and Nature, when applied to economy-as Adam Smith did (1723-1790) - automatically rejects Man's free will. But if a man is free to choose, as he/she is, forecasting is even more difficult (Priesmeyer, 1992) [15]. Priesmeyer (1992) [15] (and after) argued that managers do not need forecasting as they are that kind of men/women to "make things happen"...

\section{The Economics of Depression}

Wolf [14] wrote that the...model "did not allow him to...", "which model"? and he also wrote that "economics, which has dominated Academe, and shaped thinking for several decades, proved useless in predicting, tackling or even imagining financial debacles (in world's most advanced economies and for as much as 8 years" A very serious accusation!

Keynes (1936) [16] wrote the "economics of Great Depression", even if he did not title his 1936 book so. Wolf (2014) [14] suggested to read Keynes, but also to read Bagehot W (1873) [17]...But if Keynes wrote such a book, why Minsky [18] - 36 years after Keynes-in 1982-asked for one? We wrote an article for 'shipping depression' based on Keynes [16]. Is this lacking book due to the fact that in the long run ${ }^{15}$ we are all dead, as Keynes wrote?

For us, one explanation for the above is that economists turned fast to growth theories, another is that economists are challenged by, and write about, current economic problems. They expect economic historians to write about past. From economic history, personally, we prefer books like that of Blaug [19] arguing that economic history should be: "a critical study of past theories".

\footnotetext{
${ }^{13}$ Soros [21] argued that today's dominant paradigm that the "financial markets tend to equilibrium, is faulty and misleading". Soros [22] argued that the concept of equilibrium is very useful, but it can be very misleading. "Equilibrium in real life rarely is achieved". Also the theory of "rational expectations" is not taken seriously outside academe...i.e. expectations consistent with a model, but not a perfect foresight, using all available information.

${ }^{14}$ Martin-associate editor etc. of Financial times, London.

${ }^{15}$ Indeed 79 years have passed since the 1929 crisis till end-2008. See Goulielmos [23], in this journal about "Kondratieff's cycles".
} 
Polish economist Kalecki [20] (1899-1970) argued that: in a depression "capitalists get what they spend and workers spend what they get". Others said that Keynes model was static, and suitable for short run, and his disciples tried to make it dynamic and proper for a long term ${ }^{16}$. Notable was Harrod (R F Sir; 1900-1978) [24], who delivered a "fundamental equation of economic growth", rediscovered by Domar E D (1914) [25]. They indicated that if the "warranted rate of growth" and the "natural rate of growth" are equal, and if unemployment is zero, this is the "golden age growth".

Another issue is writers to challenge the mainstream theory if it shows obvious departures from real economic life. We believe that only Keynes [16] challenged the mainstream theory of his time in 1936 for good reasons. He said that the (fundamental) assumption of economists-before him-that full employment is the true economic model, (the "attractor"17, in Chaos theory language), and that it tends towards it, is wrong. Keynes [16] wrote that the existing model, before his book was published, was not "general"18, but "partial". He saw the great disagreement between existing theory and 1929 Great depression ${ }^{19,20}$. Keynes said [16] that his book primarily was addressed to his fellow economists...(i.e. the "orthodox economists" and "classical theorists"), who for him "lacked clearness and generality in their premises...in their basic assumptions" (Keynes writing in Dec. 13, 1935, in his book [16]). Keynes' 1936 remarks sound familiar today...

\section{Business ${ }^{21}$ and Shipping Cycles}

Keynes (1936 [16]) devoted one chapter only on "economics of business cycle". This probably was due to the fact that he had published 12 papers on cycles-as mentioned. The cycle-for him-is due to "marginal efficiency of capital-MEC", and-par excellence-to the "expected yield" from it, as well to the confidence level

\footnotetext{
${ }^{16}$ Worth noting is that the problem of the "distribution of income"- as the unique purpose of economics—as advanced by Ricardo (1772-1823)—long prior to Keynes-faded away. Marx, however, did not forget it, but used it.

${ }^{17}$ The "attractor" is made up by a "set of points" in a phase space (= a mathematical space of present, future and past); the orbits of such points tend towards the attractor asymptotically over time, for a broad set of "initial conditions". The area round the attractor is the "basin of attraction", and indicates the "set of initial conditions" that eventually lead to it. Let us have 2 golf balls laying in the bunker area in 2 (initial = starting) positions; when the balls are struck, they are heading towards a hole in the "green area" (="basin of attraction")-the "hole" stands for the attractor.

${ }^{18}$ This is why he titled his book: "The General theory of"...Keynes [18].

${ }^{19}$ It was this aspect that Keynes agreed with Marx (1818-1883): “Capitalism can create depressions"! Economists have to fix it-as "economy's engineers". Since the time of Marshall A (1842-1924) [26] economists tried to interpret reality; Keynes was a pupil of Marshall. It is not without meaning that economics was named first "political economy"...where attention was then on the "political motivations of economic policies".

${ }^{20}$ Once, a famous Japanese mathematical economist delivered a lecture in London, and I was there, as a doctoral candidate, and also Mrs. Joan Robinson. She asked him for his mathematical model with the endless equations on the blackboard, following the Cambridge tradition we believe: "what about real life?" He replied: "this is real life, Madam".

${ }^{21}$ Cycles show the fluctuations in the level of economic activity-of GDP or GD Income-in a regular pattern, with an expansion followed by a contraction and then by a further expansion.
} 
supporting it.

Keynes' argument can be presented as follows: $1^{\text {st }} \rightarrow$ assume that one firm - having animal spirits ${ }^{22}$ - formed expectations about obtaining-say a $20 \%$ net profit-from a "planned investment"; $2^{\text {nd }} \rightarrow$ firm's confidence level that these expectations will become true, let us assume to be $100 \% ; 3^{\text {rd }} \rightarrow$ so, the expected MEC will be $20 \%$ (which is > than the borrowing rate of interest/cost of capital, say $5 \%$, plus country risk say $8 \%$; total $=13 \%) ; 4^{\text {th }} \rightarrow$ the firm decides to carry-out this investment expecting a confident yield of $20 \%$. If now firm's level of confidence falls to half the original one, i.e. $-50 \%$, so the $20 \%$ becomes $10 \%$, this investment will not be carried-out (because $10 \%<13 \%$ ).

Worth noting is that we placed animal spirits prior to an investment plan! Surely animal spirits are required for firms to form investment plans in the first place; alternatively, they remain inactive. One may ask: but do animal spirits exist during a depression? Surely, depressions create opportunities, meaning higher MECs. And this despite: a lower confidence level, a higher risk factor, a lower cost of capital, with liquidity being the only problem...This is so because opportunities work direct on the "expected MEC". In a depression, the expected operating cost is lower, because capital goods are cheaper, and wages etc. are lower, as there is unemployment ( $1 \mathrm{~m}$ persons for Greece in 2017). This explains why investments take place during a depression... and this is true also for shipping. Moreover, liquidity ${ }^{23}$ is not the problem, if the sector entering into a depression (like the end-2008) prior was in a (exceptional) boom...(2003-2008).

\subsection{Cycles in Maritime Industry}

All maritime economists say: shipping markets are cyclical; i.e. they encounter periods of high rates (prices) and periods of low ones. A good question is: are the periods of good times equal to those of bad times? Unfortunately, not.

Research, originally, ignored cycles as it thought to be phenomena that "come and go", like the weather. Then noticed that cycles "come, go, but return"...Today, cycles are tidily classified in short, medium, long and secular (=near a century), (Goulielmos, 2017 [24], in this journal, discovered shipping's "over-secular" cycles, i.e. > 100 years), and are explained-after they happenedhow and why occurred...What surely is lacking is: "when cycles come, when ${ }^{22}$ Entrepreneurs are people with innate urge, (animal spirits), to start new businesses and take risks. On them, capitalist systems depend for the creation of new capital (= investment). But the net profit from an investment depends on effective (money) demand for its products/services. A lower effective demand out of austerity programs, lower wages, higher prices, and taxes, does not help. One solution is to create new capital in exporting industries like Tourism, Shipping and others. In case an economy has a debt, the state is unable to make investments, as most of the taxes are used to repay it (Greece). If an economy depends heavily on imports (Greece imports $70 \%$ of all products; and it imports also oil) from high-pricing countries, then a high cost of living is present along with a lower purchasing power (stagflation)...The obvious measures are: reduce imports, and replace them with national production; boost investments-preferably by buying know-how; improve the level of confidence; provide low interest credit to new capital; provide stability in business environment to help favorable expectations and achieve a low country risk.

${ }^{23}$ Banks and stock exchanges are reluctant to help after a depression, which is a wrong and myopic policy. 
cycles go, when cycles come back and when cycles turn"...This means that forecasting business cycles' timing, and their turning points, are missing, but at the same time these are very important.

\subsection{Cycles in Shipping Economic History Since 1741}

Shipping history has taught us that between 1741 and 2015 (274 years), a shipowner-if lived so long- had to face $\sim 27$ cycles, 1 every $\sim 10$ years on average (Figure 1).

Does this 10-year average cycle mean that shipowners have to amortize a new ship within her first 10 years in anticipation of a cycle? Ships, as we know, are built to live for as long as $30+$ years. Should this change? The car industry-we know this by experience-produces less durable cars as time goes-by.

More important is what Keynes wrote ${ }^{24}[16]$-in relation to durability of assets: "...we have a substantial reason (to believe) that the duration of (a) slump (has) a definite relationship to...the durability of assets". This idea is based on the assumption that the scarcity ${ }^{25}$ of durable goods raises MEC, and creates needs for new investment. It is here that technical change comes-in if it makes existing capital goods obsolete. However, the myths in connection with business cycles will occupy us also in the next section.

\section{Myths about Business Cycles}

"Cycles-for assets providing services-last the same over periods of different states of technology". We have seen that: Sailing ships cycled over $~ 15$ years; tramp ships over $\sim 9$ years and bulk shipping over $\sim 8$ years [3]. (2) "Cycles are symmetrical-run $\mathrm{x}$ years up and exactly $\mathrm{x}$ years down ${ }^{26 "}$. This version of the duration of cycles given also by Stopford [3], keeps shipowners and shippers happy, as it indicates that bad times = good times (Figure 2). But this is not true.

As shown, ABC = CDE. In addition, Pearce (1992, [27] p. 431) indicated that a cycle period is $\mathrm{AE}=2$ equal segments, measured from trend line. So, a trade cycle starts from a cut of the curve of the relevant variable (e.g. of GDP or freight rates index) with trend line (at A), goes up to peak (at B), and turns down-contracting - and cutting trend line (at $\mathrm{C}$ ) to reach its lowest point (at D) (the contraction period is from $\mathrm{B}$ to $\mathrm{D}$ ); the expansion starts from $\mathrm{D}$ up till it cuts trend line at $\mathrm{E}$ and beyond till a new peak $(\mathrm{F})$ is reached.

Figure 3 presents the actual (of different durations) "peaks" and "troughs" in ${ }^{24}$ Rephrased slightly by author.

${ }^{25}$ Existing capital becomes smaller by: decay, obsolescence and use. A smaller new capital than existing savings needs to be increased (savings < investment). In shipping obsolescence may be also legal (e.g. from IMO regulations some ships, like those tankers of single skin/single bottom/hull etc. had to be scrapped). Scrapping (and ships lost), however, is not automatic in shipping, but it may take 3 years thinking time according to our research. This waiting time surely shapes slump's duration making it longer; ships with 30 years plus life on average do not help in the eliminations of cycles... as they will be there for 2 additional cycles. If a ship is amortized in 10 years and scrapped when cycle starts, due to demand, supply is not held responsible for it.

${ }^{26}$ This myth led the shipping company "Sanko steamship Co of Japan" to an almost catastrophe. 


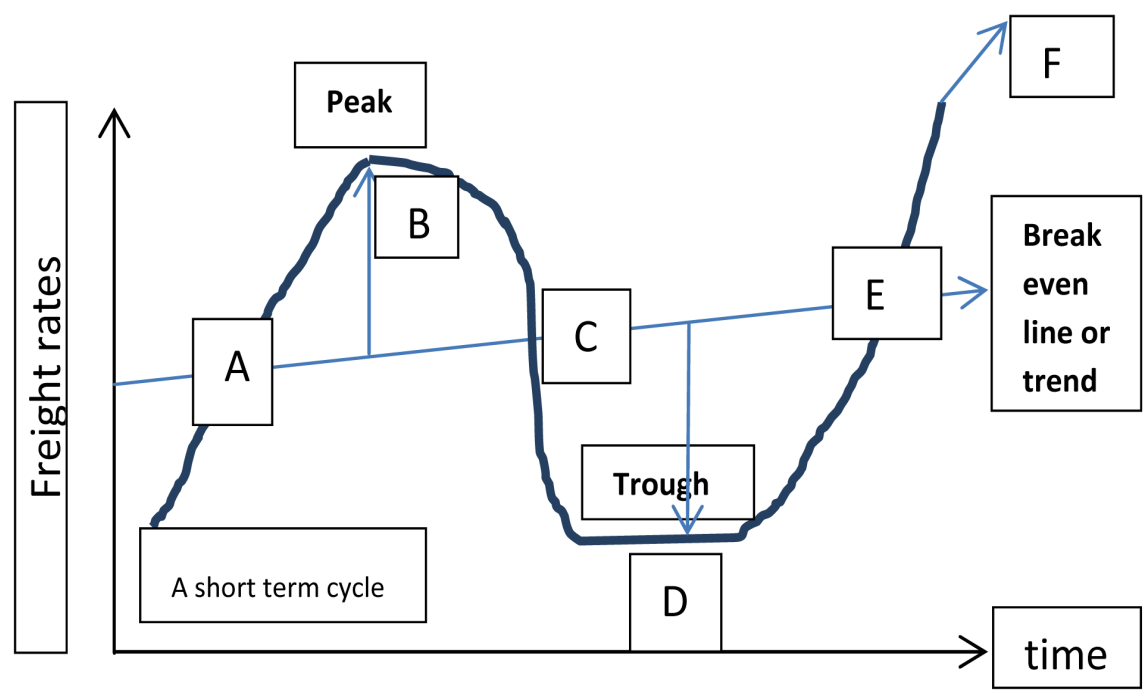

Figure 2. Peak period $=$ trough period in a shipping cycle. Source: Reproduced from Stopford (2009, [3] p. 102).

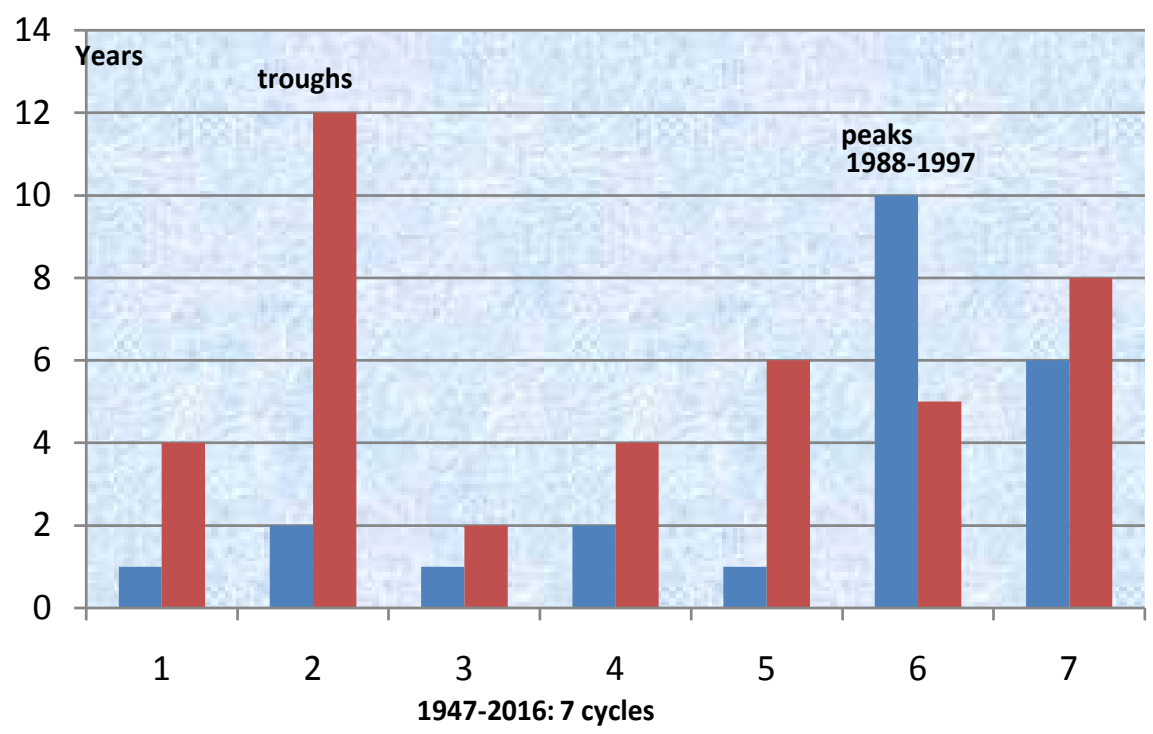

Figure 3. Troughs and peaks in shipping cycles, 1947-2016. Source: Data from Stopford (2009, [3] p. 106).

the shipping sector, from 1947 to 2016.

As shown, all peaks last less than 6 years and most (70\%; five of them) last 2 years or even less (one year); the only exception is the 1988-1997 peak (10 years!). The troughs lasted longer than peaks, as expected, with the highest in 1958-1969 (12 years!). Good things do not last forever! Maritime economy is like life.

"Cycles were known-for the first time-in Jevons' time" (1835-1882). Jevons explained trade cycle in terms of harvest's fluctuations due to weather (Sun's spots; rain), a theory sympathized by Keynes! This was called a "real cause' theory". Keynes had also advanced a psychological theory of cycles. Monetary 
theories of the cycles were advanced by Hawtrey (1879-1975); over-production and under-consumption theories were advanced by Hobson (1858-1940); saving-investment theories were advanced by Keynes [16]. One phenomenon, many different theories...

- Cycles in Bible ${ }^{27}$

Theory, however, missed, for a very long time, the fact that Bible mentioned the first cycle (of harvests) in history at the time of Joseph, son of Jacob, when he was in Egypt...As Mandelbrot and Hudson wrote [2], market's wild trait-the almost cycles-is prefigured in the story of Joseph, where 7 years of famine followed by 7 years of prosperity...

"Regular" cycles, as in Bible, very much appealed to ancient Greeks, who believed-wrongly - that Nature preferred the perfect circles; this was not true as we know now that planets orbit in non-circles; victim of this was also Aristotle (384-322 BC), who created a model of the universe based on the heavenly bodies' moving in perfect circles. Victims were also Ptolemy $\left(2^{\text {nd }}\right.$ c. A.D.) and Newton (1642-1727) [2] [28].

\section{Myths in Time Series}

In time series analysis similarly the focus is also on regular, periodic, cycles. In "Fourier analysis" e.g., the irregularly shaped time series are the sum of a number of periodic sine waves; spectral analysis too [29] breaks an observed irregular time series into sine waves.

The myths in detail are: 1) time series do not cycle, 2) time series do not remember...3) Time series behave as "bell"28 curves, and have slim tails or low peaks and 4) time series are only linear. The "Bible cycle", mentioned above is e.g. a case of a long-term memory in time series, through which the past continues to influence the random fluctuations of the present. It named apropos by Mandelbrot: the "Joseph Effect". More important is that this indicates a unique property, tendency, of only (persistent) time series, to produce cycles... Very interesting. How can we distinguish persistent time series with this special property to cycle?

\subsection{Persistent Time Series}

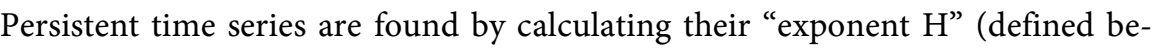
low). Letter $\mathrm{H}^{29}$ is given to this exponent-after Hurst's name ${ }^{30}$-by Mandelbrot. Hurst used letter K. Now, an H larger than $0.50 \leq 1$ indicates that data are "per-

\footnotetext{
${ }^{27}$ Bible showed that God is also a "shipowner" as made $2 / 3$ of earth covered by sea; he is also a "ship designer", as instructed Noah how to construct Ark. He is also a mathematician applying "fractal geometry"...

${ }^{28}$ Meaning "normal distribution".

${ }^{29}$ This is a measure of bias, in the "fractional Brownian motion". The Brownian motion is a Gaussian process with independent non-overlapping increments named after Robert Brown (1773-1858) - a botanist, who in 1827 first observed under a microscope the random movement of pollen or dust particles floating in water.

${ }^{30}$ Due also to the pure mathematician: Mr. L O Holder.
} 
sistent" ${ }^{31}$. Also, its statistical test can be done through the (non-parametric ${ }^{32}$ ) "rescaled range analysis", or the range divided by local "standard deviation".

\subsection{A Story of the Discovery of $H$}

The case where $H$ is $=$ to $1 / 2$, proved mathematically by Einstein $^{33}$ [30]. He proved that the distance: $D$, which a random particle ${ }^{34}$ covers, increases by the square root of time (used in measuring it): so, $D=\operatorname{Time}^{1 / 2}=\sqrt{t}=t^{0.50}\{1\}$, where "time"- $t$-stands for the time index ${ }^{35}$.

Hurst $^{36}$ [31] showed that $(R / S)_{n}=C * n^{H}\{2\}$, where $R / S$ is the 'rescaled range', (with zero mean and a local standard deviation $S$ ), divided by $S$; the (adjusted; nonnegative) range $R_{n}$ now is $=$ to $\max \left(Y_{1}, \cdots, Y_{n}\right)-\min \left(Y_{1}, \cdots, Y_{n}\right) \quad\{3\}$, which gives the distance that a system travels for time index $n$; where $c$ is a constant; $H$ is the Hurst exponent and $n$ refer to the $R / S$ values for $\left(X_{1}, \cdots, X_{n}\right)$ time series [32]. Taking logs on $\{2\}: \log \left(R / S_{n}\right)=\log (c)+H * \log (n)\{4\}$. $\{4\}$ is used to estimate $H$.

\subsection{Testing the Value of $H$}

To test the above theory, we used 256 (265-1 for $1^{\text {st }} \log$ differences -8 yearly figures were lost due to war: 1939-1946) yearly observations (1741-2015), already presented in Figure 1, and we have applied above regression $\{4\}$ (using least squares), and found ${ }^{37}: H_{n \geq 10}=0.685823=0.69$ (rounded) $>0.50 \leq 1$, indicating persistent maritime time series.

\subsection{Testing If Time Series Have a Memory}

The probability for a memory is given by ${ }^{38}: V_{n}=(R / S)_{n} * \sqrt{n}\{5\}$. Here the ${ }^{31}$ Alpha measures how tall a peak in a probability density function is; it ranges from 0 to 2 (closed interval). Also, $H=1 / \alpha=0.685823=1 / \alpha$ and $\alpha=1.4581022$ ( 1.46 rounded $<2$ for normal distribution). Proof. Let $R_{n}$ be the sum (of the $n$ values) of a stable variable in a particular interval $n$ (Peters, 1994 [28]), having an initial value of $R, R_{1}$, and scaling as $n^{1 / \alpha}$, times $R_{1}: R_{n}=R_{1} * n^{1 / \alpha} \quad\{1\}$. Taking logs of $\{1\}$ and solving for alpha, we get: $\alpha=\log (n) / \log \left(R_{n}\right)-\log \left(R_{1}\right) \quad\{2\}$. Given that $1 / H=\log (n) / \log (R / S) \quad\{3\}$ and assuming that $R_{n}-R_{1}=R / S \quad\{4\}$, then $\alpha=1 / H\{5\}$. The "fractal dimension" of a time series is also equal to $2-\mathrm{H}$. Here: $2-0.685823=1.314177$ (1.31 rounded), which gives the fractal dimension; indicating a non-integer number.

${ }^{32}$ There is no need to make simplifying assumptions about how data are organized.

${ }^{33}$ Einstein [30] solved the problem posed by Brown in 1827-8. Robert Brown studied the erratic movement of a small particle suspended in a fluid and said that this was due to fluid. Einstein [30] showed that this was due to water molecules colliding with the particle. Weiner $N$ (in 1976) (collected works, Vol. 1, edited by Masani from MIT Press) modeled "Brownian motion" as a "random walk" with an underlying Gaussian statistical structure, called also Wiener process.

${ }^{34}$ Scientists included "random time series" - though not continuous-with zero mean and variance equal to 1 , called reduced Gaussian; and be independent for increasing values of time index $n$.

${ }^{35}$ If we replace $n$ by $T ; H$ by $1 / 2,(R / S)_{n}$ by $D$ (distance), and $c=1$, then: $D=T^{0.50}$, which is Einstein's equation, coming as a special case. Regnault [33] argued (in Mandelbrot and Hudson, 2004 [2]) that there is a mathematical law, which regulates the variation and the mean deviation of stock market prices: "stock price deviation is directly proportional to the square root of time" [34].

${ }^{36}$ Hurst [31].

${ }^{37}$ Using MATLAB 1989-and NLTSA in 2000 computer program [35]—we took $1^{\text {st }}$ logarithmic differences for time series to be stationary. The first 9 observations are disregarded as the system needs first stabilization.

${ }^{38}$ The $\mathrm{V}$ distribution is given by: $F(u)=1+2 \sum_{k=1}^{\infty}\left(1-4 k^{2} u^{2}\right) \mathrm{e}^{-2(k u)^{2}} \quad$ due to Lo [36], where $u=$ the mean of $V_{n}$ for all $\mathrm{n}$. 
probability of the above time series to have a long term memory-shown by $\{5\}$ - found equal to 0.92098 (however 0.92 rounded $<0.93$ rounded, which corresponds to only a $10 \%$ probability for a memory) following Lo's [36] table.

\subsection{Detecting Time Series Cycles}

As argued by Peters [28], in Chaos theory, non-periodic cycles exist with an average duration. $R / S$ can detect periodic cycles too. This is so for periodic cycles the range $R$-defined above-could never grow beyond the amplitude of the relevant wave, and so $R / S$ would reach a maximum after one cycle. The first cycle in our data is 84 years as shown below (Figure 4).

Figure 5 gives a better estimate of the cycle length by presenting the results from equation $\{5\}$. Equation 5 originally was used by Hurst to test for stability,

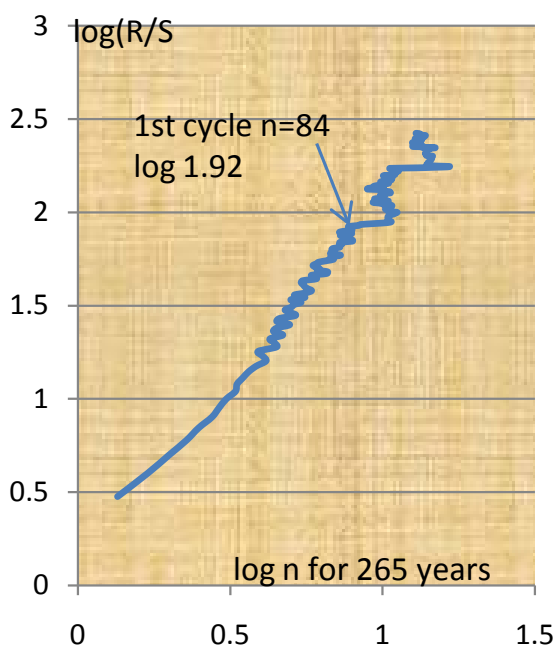

Figure 4. $\log (\mathrm{R} / \mathrm{S})$ versus $\log (\mathrm{n})$ Source: Data used as in Figure 1 from Stopford [3] and NLTSA (2000) [35] program, excel 2010.

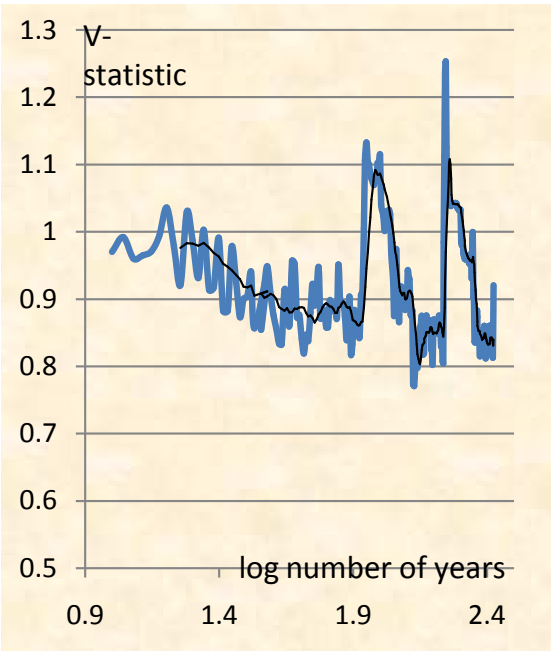

Figure 5. V-statistic versus $\log$ n. Source: Data used as in Figure 1 from Stopford and NLTSA (2000) [35] program, excel 2010. 
and it works particularly well in the presence of noise. The plot of $\mathrm{V}$ versus $\log \mathrm{n}$ (Figure 5) is flat if the process is random. This is not true for the whole range of the maritime time series used here (1741-2015).

\subsection{Time Series Have No Fat Tails or Tall Peaks}

An alternative picture is given by Figure 6 presenting coefficient $\alpha$. If $\alpha=2$, time series are random. As shown in Figure 6, the curve deviates from alpha $=2$ at various times; the deviation is stronger from $223^{\text {rd }}$ year till end-2002, where $\alpha \rightarrow$ 1.46 (rounded). This points towards $(1741+223$ years +8 years for which data is lost) approximately years 1971-1972. During these years and after, randomness disappeared and risk increased in shipping...(Figure 6). Shipowners in age round their 50s today had to be more careful, as dry cargo markets became very tough since 1971-1972. After 1971-1972, indeed many (five) peaks occurred: 1973-1974; 1979-1981; 1988-1997; 2003-2007; 2008; out of 9 since 1947.

\subsection{The Bell Curve}

The last myth is that the probability of an event-occurring in a given population - fulfilling some basic conditions-is given only by bell curve. Let $x$ be a variable's level that we want to study; let the Greek letter $\mu$ stands for the average value of all $x^{\prime}$ s in the population; let $\sigma$ stands for the standard deviation -indicating the degree of how broadly $x^{\prime}$ s, around $\mu$, are scattered; then the bell curve is: $f(x)=1 / \sigma \sqrt{2 \pi} * \mathrm{e}^{-((x-\mu) / \sigma)^{2} / 2}$ (known also as normal distribution) $)^{39}$.

Now, if $x$ is close to $\mu$, the probability for this to appear is high. The opposite will hold if $x$ is found in tails. Standard deviation, $\sigma$, determines if the curve will

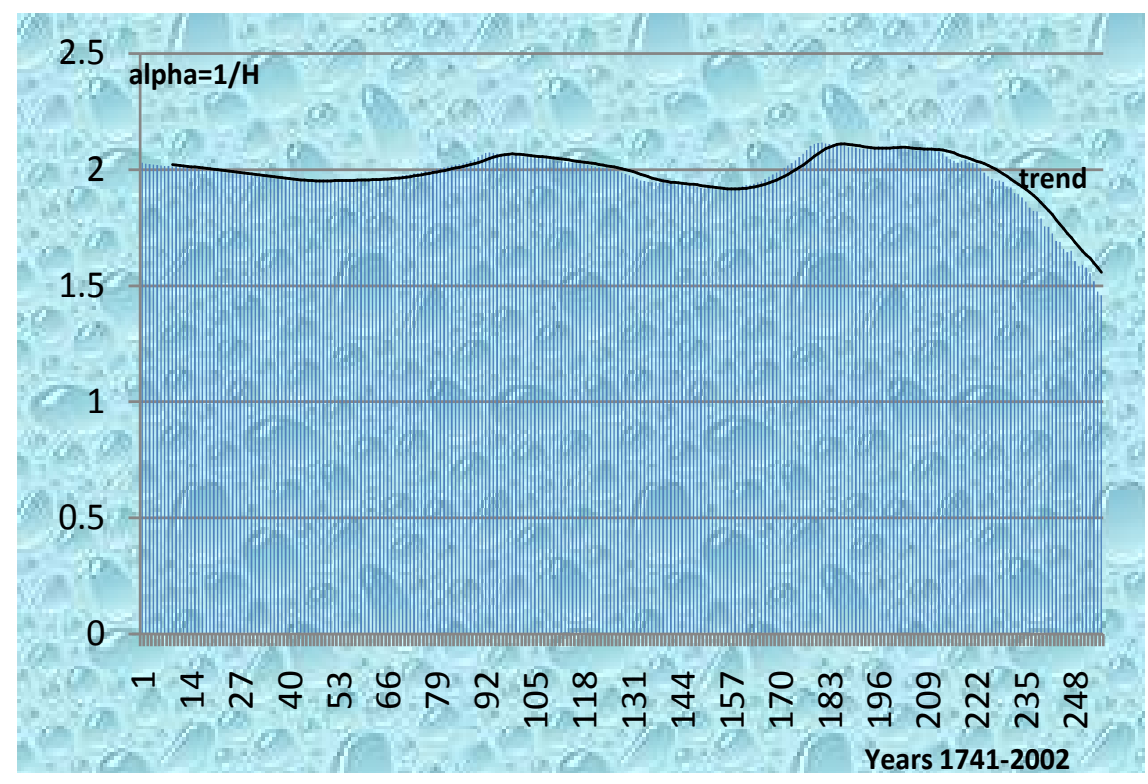

Figure 6. Alpha- $\alpha$-coefficient versus years, 1741-2002, derived from 1/alpha $=\mathrm{H}$ ).

${ }^{39}$ Where e is a constant, (an irrational number), with infinitely non-recurring digits starting as 2.7182 . 
be squat and low, or narrow and tall. The myth that the bell curve is the unique one for time series is false. In fact there are another two interesting ones (Figure 7).

As shown, the more flat curve-the bell-does not go beyond the 2 points indicated by the 2 arrows on the right and left tail; or in statistical language, the curve does not go beyond $\pm 3 \sigma$ from the mean $\mu$. The two other curves do. This means that the probability of $x$ to get extreme values -like over $\pm 3 \sigma$ s from the mean $\mu$-is only $\pm 0.25 \%$. It is thus very important to know what type of curve time series under study follows.

\subsection{Facts That Have Rejected the Bell Curve Model}

The "Dow Jones Ind. Index" had many changes beyond $5 \sigma, 10 \sigma$ (1930-1935) (2000 and after), and even $22 \sigma$ (1987; black Monday) (Mandelbrot and Hudson, 2004, [2] p. 93-94). This happened also in shipping industry 9 times since 1914: in 1914: $4.57 \sigma$, in 1920: $3.45 \sigma$, in 1950: $3.06 \sigma$, in 1970: $3.28 \sigma$, in 1972: $4.9 \sigma$, in 1973: $7.04 \sigma$, in 1974: $3.65 \sigma$, in 2004: $5.23 \sigma$, and the highest $9.56 \sigma$, in October, 2008 meltdown [37]. Moreover, the freight rates obtained by a vessel between 1989 and 2008 (1043 weeks) [37] showed a right fat tail going up to $+4.65 \sigma$.

\subsection{The Key Parameter Is Alpha}

Alpha appears in the formula of the broader L-stable characteristic function (or L-stable probability distribution): $\log f(t)=i \delta t-\gamma|t|^{\alpha}[1+i \beta(t /|t|) \tan (\alpha \pi / 2)]$, [written in Mandelbrot and Hudson [2]. This curve has 4 key parameters that determine its shape. In fact these parameters determine whether we have a bell curve, a Pareto-style one, etc.: delta- $\delta$-is the location parameter; gama- $\gamma$-is the scale parameter, determining the magnitude of probabilities overall; beta- $\beta$ - determines skewness: if 0 , the curve is symmetrical like bell; alpha determines the amount of "fat" in the tails. If $x$ lays $22 \sigma$ from the mean (as in 1987), the fat is quite significant.

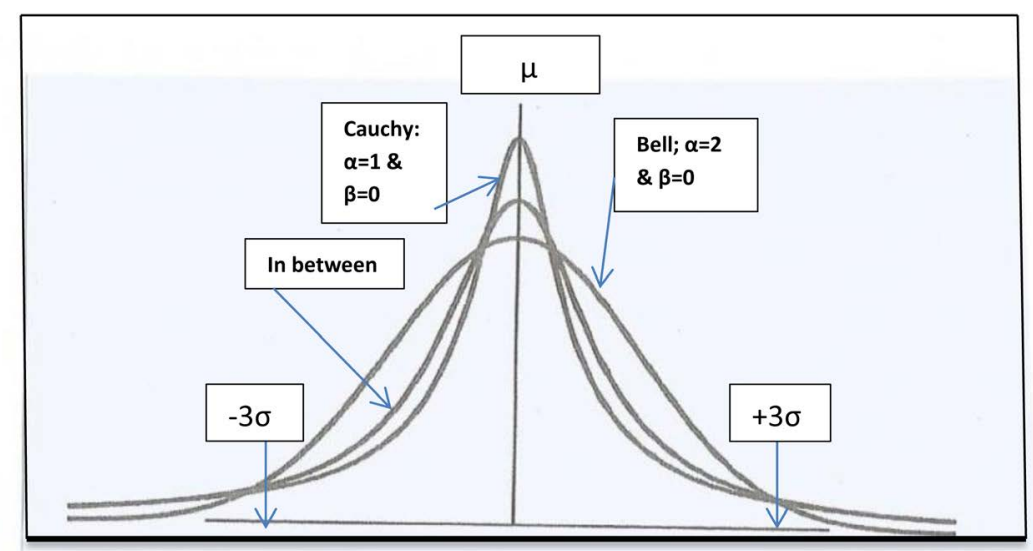

Figure 7. The "bell" curve, the "Cauchy curve" and the "in-between shipping and finance curve". Source: inspired by Mandelbrot and Hudson [2]. 
In Figure 6 we showed that maritime alpha ${ }^{40}$ tended to 1.46 (rounded). This is best presented by the in-between curve, (Figure 7), not by the bell! Mandelbrot and Hudson [2] found alpha $=1.70$ for cotton prices, and characterized these as subject to "strong variation". Maritime prices, however, were wilder after ${ }^{41}$ 1971-1972, than cotton prices, as shipping alpha $\rightarrow 1.46<1.70 \ldots$

\section{Myths about Shipping Forecasting}

\subsection{Are Time Series Only Linear and/or Nonlinear?}

First myth is that the exclusive "appropriate" time series models ${ }^{42}$ are linear ${ }^{43}$ (autoregressive- $A \mathrm{R}$ model; GARCH). Very important is that the models $\left\{\begin{array}{lll}1 & \& & 2\end{array}\right\}$, shown in footnote 42 , are unable to explain a number of important features shown by shipping and finance time series such as: leptokurtosis (fat tails; excess peak); volatility clustering or pooling (where volatility appears in bunches); leverage effects (where volatility rises more in large price falls) [40].

Dealing with this matter for a long time, we found, in many shipping papers, that shipping time series behave as those in finance. Jing et al. [41] argued apropos that the daily returns of BCI, BPI and JEHSI, indices for Cape, Panama and Handy-sized ships-though found non-normal by the Bera and Jarque [42] test-have the typical features of stock returns, i.e. fat tails and spiked peaks (for 01/03/1999-23/12/2005)!

As argued by Peters [28] and by K Syriopoulos [43], a very important characteristic of finance-and shipping, we add-time series, is their "nonlinear dependence", measured by $\mathrm{H}$. This leads the classical linear analysis of time series in relative ineffectiveness. If the linear dependence, or zero hypotheses, is rejected, then time series can be non-stationary, obey a low-dimensional chaos and as well having other properties. The existence of a low dimensional chaos, i.e. < 10 variables, permits forecasting...

\subsection{A Test of Nonlinearity}

A test of nonlinearity-as concluded from the above-would apparently be useful. One of the widely used tests ${ }^{44}$ is the BDS one [44]. This last test assumes that data are completely random, or depart to deterministic chaos etc. Goulielmos and Psifia [37] applied this to shipping time series and found them non-IID ${ }^{45}$ ${ }^{40}$ Alpha measures how wildly prices vary.

${ }^{41}$ One may count at least 7 country crises after 1994: Mexico (1995); Thailand, Indonesia (severe), S Korea (1997-1998); Russia (1998), Brazil (1998-1999) and USA-globe (2007-2008).

${ }^{42}$ Time series-econometrically-fall in a structural (linear) model: $y=\beta_{1}+\beta_{2} x_{2}+\beta_{3} x_{3}+\beta_{4} x_{4}+u$ $\{1\}$, or in a more compact form: $y=X \beta+u\{2\}$ where $u_{t} \sim N\left(0, \sigma^{2}\right)$, presenting a straight line.

${ }^{43}$ Following Campbell et al. (1997 [38]), a non-linear model is given by:

$y_{t}=g\left(u_{t-1}, u_{t-2}, \cdots\right)+u_{t} \sigma^{2}\left(u_{t-1}, u_{t-2}, \cdots\right)$ where $g$ is a function of past error terms only, and $\sigma^{2}$ can be interpreted as a variance term. Thus there are models with non-linear g (i.e. nonlinear mean; like GARCH) and with non-linear $\sigma^{2}$ or both mean and variance, like ARMA and CLRM (classical linear regression model).

${ }^{44}$ Also Ramsey's RESET [39]. This is the Ramsey's regression equation specification error test. It tests whether non-linear combinations of explanatory variables-and their powers-help explain the dependent variable.

${ }^{45}$ IID stands for independent and identically distributed variables with mean $\mu$ and variance $\sigma_{x}^{2}$. 
with confidence level $99.5 \%$ for embedding dimensions from 2 to 5 and radius values from $1 / 2 \sigma$ to $2 \sigma[45]$.

\subsection{Seaborne Trade Forecasting}

Whoever can forecast demand (= seaborne trade) is King in shipping. But, tiny deviations of seaborne trade, however, give huge amounts of tons required to be transported... due to the different scales of demand and supply. Stopford (2009; [3] p. 718 and after) forecast seaborne trade over 1996-2005, fitting a linear regression model on data regressing seaborne trade on global GDP:

$\mathrm{ST}_{\mathrm{t}}=a+b \mathrm{GDP}\{1\}$; he found $\mathrm{ST}_{\mathrm{t}}=-26.289+30.9 \mathrm{GDP}_{\mathrm{t}}\{2\}$, which indicates that for 1 point increase in global GDP, seaborne trade rises by $\sim 31$ million tons, with a correlation coefficient 0.99 .

The above regression used by Stopford (2009 [3]) to predict seaborne trade from 1995 to 2005 . The 2005 prediction gave 6.79 billion tons, where the actual was $6.78 \mathrm{~b}$ tons. The difference was $10 \mathrm{~m}$ tons. This thus underestimated demand by 200 ships of 50,000 net dwt each $(200 * 50,000=10 \mathrm{~m} \mathrm{dwt})$. This, however, cannot be considered as a successful forecast as considered by Stopford [3].

In shipping, it matters the size of what is predicted as a tiny deviation of only $\sim 0.15 \%$ - as in this case on 6.79 billion tons sea trade-means a $\sim 10$ million tons demand for ships... Predictions by Stopford (2009 [3]; p. 719) for "oil trade" and "dry cargo one" deviated more than in the case of total seaborne trade, i.e. by $-400 \mathrm{~m}$ tons and $+300 \mathrm{~m}$ tons respectively for 2005 ! The ships required in this instance for dry cargoes were 6000 additional ones (of 50,000 net dwt each) and for oil 8,000 ships were not needed...

\subsection{Nonlinear Forecasting}

For shipping time series, our interest is on "nonlinear dynamics" mentioned-is if the "Random Walk" hypothesis is valid, i.e. if $X_{t+1}=X_{t}+U_{t}$ [weak form], where $X_{t}$ stands for $\log X$ at time $t$ and $U_{t}$ stands for a white noise process [46]. Using Bera and Jarque [42] test it would be easily to show that almost all shipping (and finance) time series do not pass normality test [41].

The methods that can be used for nonlinear forecasting are five ${ }^{47}$. Eight applications from 1990 to 1999 (not mentioned here, but in NLTSA 2000 [35]) showed that forecasting a time series "looking as if it was random" (=chaotic), gave better ${ }^{48}$ results than by using an autoregressive model-AR(1).

\footnotetext{
${ }^{46}$ Because all investors think differently, where some have short term expectations, others medium and still others long; also a piece of information may be taken-for differently by investors as an opportunity or as a threat. The feeling of fear is also different after a portfolio's value rises or falls.

${ }^{47}$ Local "ordinary least squares", due to Farmer and Sidorowich (1987 [48]; "principal components regression" due to Sauer (1993 [49]); "radial basis functions", due to Casdagli [50]; "kernel density estimation", due to Sugihara \& May (1990 [51]), and (5) "ridge regression", due to Kugiumtzis D et al (1998 [52]).

${ }^{48}$ Theory suggests using NSR, i.e. the "error estimator", to select between methods. NSR is given by: $E=\sqrt{\sum\left(x_{p}-x\right)^{2} / \sum\left(x_{\text {mean }}-x\right)^{2}}$, where $x_{p}$ is the predicted value of $x$, and $x_{\text {mean }}$ is the mean of all observations including $\mathrm{x}$; E empirically varies between 0 and 1 . The best prediction is when $E=0$; if $E=1$ time series are most probable random and the best prediction is its mean.
} 


\subsection{A Different Approach to Forecasting}

Here we will use a different approach: using the time series up to 2008, presented already in Figure 1, we will forecast inside the sample the last 7 years (2009-2015) $(\mathrm{n}=260-1)$ with all five methods (Table 1). Since we know the actual figures for 2009-2015, we will find out which method gives the closer predictions. Then we will use this method to forecast next 5 years (2016-2020) outside the sample.

As shown, KDE gives predictions closer to actual, except for 2010, where PCR is better (the closer predictions are highlighted). In all 5 methods of Table 1, we assumed embedding dimension 5; time delay 1 and the number of nearest neighbors equal to 16 . These values were selected based on our previous experience [47] and many tests carried out inside the sample by trying different coefficients; except for time delay $=1$, which is recommended by NLTSA [35] computer program.

KDE stands for the Kernel density estimation. Forecasts with this method are given by $X_{(N+1) \text { rediction }}=\sum_{j=1}^{k} W_{j} X_{j}+p+(m-1) T\{1\}$, where-if possible$\sum W_{i}=1 . W_{i}=f\left(R_{i}\right) / \sum f\left(R_{j}\right)\{2\}$, where $j=1$ to $k . R_{j}$ are the distances to which we attach a weight $f\left(R_{i}\right)=\exp \left\{-R_{i}\right.$ (square) $\left./ c^{2}\right\}\{3\}$, where $c$ is the mean of $R_{i}$. For the last point $\boldsymbol{X}_{T}$ (bold stands for a vector), we select the $k$ nearest neighbors $X_{p}$ where $j=1(1) k . m$ stands for the embedding dimension, the time delay is $\mathrm{T}, \mathrm{k}$ is the number of the nearest neighbors and $p=T-k$.

$\mathrm{KDE}$ ( $n=259$ years) gave the following forecasting outside the sample for 2016-2020 (Table 1; Figure 8): 2016: 175 (improved 192); 2017: 172 (190); 2018: 173 (188); 2019: 170.5 (179) and 2020: 157 (167.4). The improved forecasts mentioned in parenthesis (and closer to real than the previous ones shown in Figure 8)

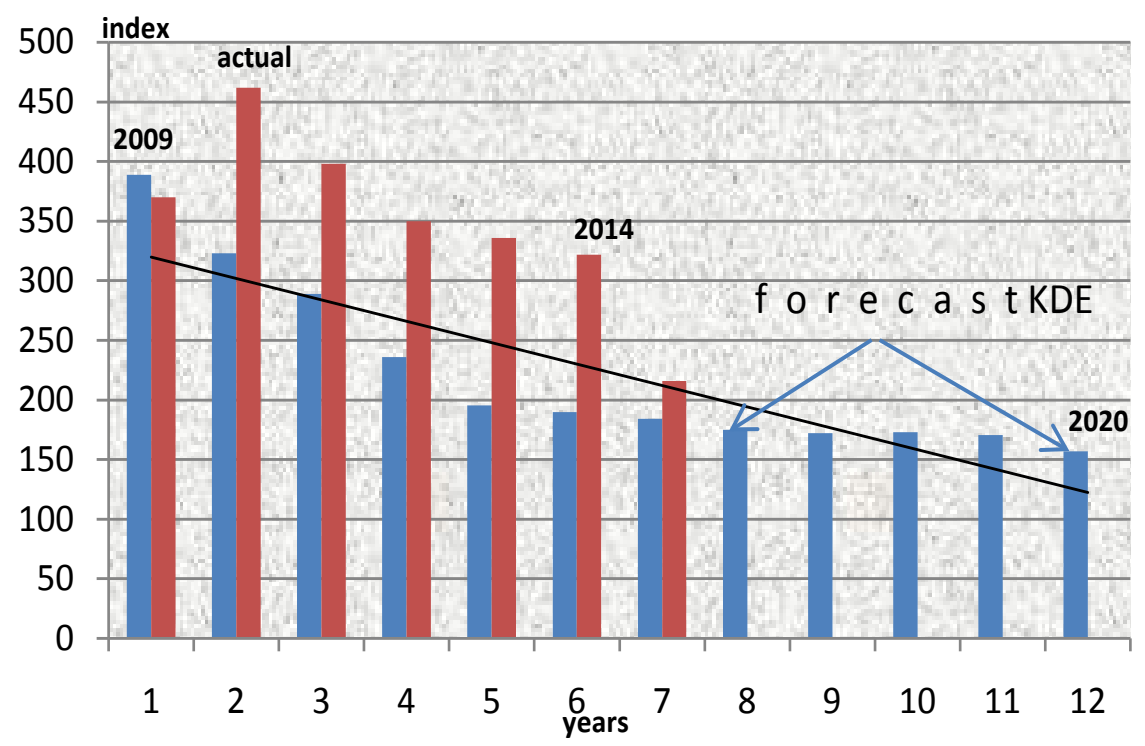

Figure 8. Forecasting the dry cargo index for 2016-2020 $(1947=100)$. Source: as in Figure 1; KDE forecasting using NLTSA (2000 [35]); excel. 
Table 1. Backward predictions of dry cargo index, 2009-2015.

\begin{tabular}{ccccccc}
\hline Year/Method: $\rightarrow$ OLS & PCR $\left(^{*}\right)$ & RR & RBF(**) & KDE & NEW KDE & Actual \\
\hline 2009: -62 & 554 & -15 & 473 & 389 & 363 & 370 \\
2010: -620 & 391 & -541 & 293 & 323 & $305.5\left(^{* * *}\right)$ & 462 \\
2011: -669 & 261 & -576 & 234 & 289 & $279\left({ }^{* * *}\right)$ & 398 \\
2012: -272 & 178 & -215 & 185 & 236 & 237 & 350 \\
2013: 165 & 135 & 163 & 104 & 195.5 & 207 & 336 \\
2014: 153 & 122.5 & 154 & 32 & 190 & 200 & 322 \\
$2015: 133$ & 125 & 134 & 21 & 184 & 194.4 & 216 \\
\hline
\end{tabular}

$\left({ }^{*}\right)$ Variance $=80 \% ;\left(^{* *}\right) \mathrm{b}=1.5 ; \mathrm{ed}=5 ; \mathrm{td}=1 ; \mathrm{k}=16 ; \mathrm{n}=259 ; \mathrm{H}=0.70$ (rounded).

obtained after changing the embedding dimension ${ }^{49}$ to 8 , from 5 , and $\mathrm{k}$ to 20 from 16. The new predictions and forecasts are shown in Table 1 marked "new". As shown 5 yearly predictions and forecasts have improved and two: ${ }^{* * *}$ and ${ }^{* * * *}$ were worse.

In more detail, the new prediction inside the sample for 2009 are even closer to actual $(+1.9 \%$ greater); for 2015 the difference -as expected- is greater, i.e. $-\sim 10 \%$. The method KDE forecast, however, the falling trend for 2009-2020. We can use here our dictum: "an up to $90 \%-98 \%$ accurate forecasting in shipping is better than no forecasting at all". Shipping is considered unpredictable and a scientific forecasting even from $2 \%$ to $10 \%$ away from reality for certain years-as above-is of substantial help, we believe. Moreover, the above predictions and forecasts do not indicate a cycle, or any turning points, but only a falling trend. This is also very important information.

\subsection{Paper's Main Contributions}

Paper's contributions are: 1) to show that many time series are persistent, and a test exists for that, and these time series are prone to cycles following trends; time series "travel" in different speeds, where Einstein's one travels at the square root of time. Have time series a memory? Do they have Long term dependence? Are they chaotic? 2) the torturing issue for me as a maritime economist for many decades is to forecast shipping cycles and their turning points; our hopes -since most of the linear models have failed as these have been tested in reality for the second time in meltdown and since 1918. As a result we have resorted to alternative models like those of nonlinear chaotic nature.

\section{Conclusions}

Forecasting depressions seems to depend on the ever improving computerized economic models used clouded in myths. But it also seems that are based

${ }^{49}$ Time series are embedded in various dimensions to attain some stabilization in the composition of the item that is formed (i.e. the attractor).

${ }^{50}$ And 12 papers between 1914 and 1940, mentioned in "Readings in Business cycle theory" (AEA, $1950[1])$. 
wrongly on the assumption that economies return to equilibrium. Keynes wrote the "economics of depression" in 1936, but he was soon forgotten, as his disciples wanted to make his theory long term and dynamic-i.e. to deal with economic growth (e.g. Harrod and Domar).

Strangely, Keynes did not deal extensively with business cycle-as he devoted only one chapter ${ }^{50}$ in his 1936 book. But Keynes established the way economic progress can be achieved, if economies have entrepreneurs...with animal spirits-seeking after a favorable expected marginal efficiency for their (new) capital investments.

Many say that cycles cannot be forecast; and that their turning points are impossible to foresee. This paper showed differently. Shipping economists have been troubled by 27 or so frequent cycles-of an average duration of about 10 years-since 1741 and till 2017. Keynes discussed the issue of the durability of assets, and we discussed the durability of ships, and their impact on the creation of new capital. This is an issue, which remains unresolved, confined in this question: "should capital goods industries construct assets with an as long as possible technical life"?

Searching the main ingredients of this paper: cycles, forecasting and time series, we stated and discussed the many myths that prevent scientists from a more realistic analysis of facts. We showed that shipping cycles are shaped by the technological state of the period; cycles are not perfect circles-as Bible, Aristotle, Ptolemy, Newton, Fourier and others believed-or symmetrical with $\mathrm{x}$ terms up and equal terms down, as believed by Bible, Stopford, Pearce and Sanko Steamship Co of Japan.

In time series used here for dry cargo market the first shipping cycle found to last 84 years. In this paper we succeeded to detect cycle's duration and their trend and whether cycles have a turning point or not, as mentioned. The myths surrounding time series are equally crucial: all data-and those of finance and shipping-are assumed to follow the "bell" curve with almost all variations/ changes falling within $\pm 3 \sigma$-but Dow "escaped" away by $22 \sigma$ in 1987 and a shipping freight rate index $\sim 10 \sigma$ in end-2008. Further myths are that time series do not cycle, have no memory and are linear. But in reality time series are persistent, moving faster than the square root of time ( $\mathrm{H}=0.70$ rounded). Time series may follow 3 distributions in fact: the bell, with alpha $=2$ and $\beta=0$; the Cauchy with alpha $=1$ and the finance and shipping ones with alpha $=1.50 \ldots$

Myths about forecasting are that forecasting methods are only linear and non-chaotic. But linear models are unable to function under leptokurtosis; volatility clusters and leverages...We mentioned and used 5 nonlinear forecasting methods. Using back-forecasting and-forward, we selected one method-the Kernel density estimation-to make predictions for 7 years inside the sample and 5 years outside it. Our results were, from $2 \%$ to $10 \%$, away from actual ones, after making adjustment to coefficients involved inside the sample. We argued that a forecasting with accuracy $90 \%-98 \%$ is better than no forecasting at all for 
the very turbulent shipping markets...

The limitation of this paper is that what is forecastis difficult to assess for its success till years forecast come into present... The whole paper is purposed to act as a strong-perhaps provoking-motivation for further research to dissolve finally all "myths" about economy-and par excellence about crucial ones like time series, forecasting and business cycles. These have come up on the surface due to the 2008 meltdown, which reminded us also of the not forecasted Great Depression in $1929 \ldots$

Is it so difficult to have one effective model of business cycles? This is a challenge for future research. Another limitation is that Chaos Theory, which we have implicitly proposed, is not universally accepted-though many authorswe have reviewed were disappointed by now-by the computer models based on bell curve. Also by the fact that the supposed tendency of economy to return to equilibrium when disturbed.

It is our hope that the 3 models presented in this paper-bell, Cauchy and in-between-showed that onedistinct model is required for when economy is mild, wild or slow. So, economy needs 3 models in order to be understood or one model adaptive for all 3 situations. Chaos theory-as showed-proposes one model with all 3 states depending on $0 \leq \mathrm{H} \leq 1$ and $1 / \mathrm{H}=$ alpha.

\section{References}

[1] AEA (American Economic Association) (1950) Readings in Business Cycle Theory, Great Britain. Selected by a Committee, George Allen and Unwin Ltd., 446-487.

[2] Mandelbrot, B. and Hudson, R.L. (2004) The (mis)behavior of Markets: A Fractal View of Financial Turbulence. Basic Books, in Paperback Published in 2006; with a New Preface on Financial Crisis Published in 2008.

[3] Stopford, M. (2009) Maritime Economics. 3rd Edition, Routledge, 695. https://doi.org/10.4324/9780203891742

[4] Beck, P.W. (1983) Forecasts: Opiates for Decision Makers. Lecture to the 3rd International Symposium on Forecasting, Philadelphia, 5 June.

[5] Seland, J. (1960) On Forecasts and Forecasters: Pitfalls of Predicting Tonnage Demand. The Shipping World.

[6] Hearth, J. (1970) Forecasting Shipping Demand. Shipbuilding and Shipping Record, 2 October.

[7] Stopford, M. (2001) Forecasting the Dry Bulk, Tanker and Container Markets. Maritime Cyprus, 23/09/2001.

[8] Lorange, P. (2009) Shipping Strategy: Innovating for Success. Cambridge University Press, 56.

[9] Eslami, P., Jung, K., Lee, D. and Tjolleng, A. (2016) Predicting Tanker Freight Rates using Parsimonious Variables and Hybrid Artificial Neural Network with an Adaptive Genetic Algorithm. Maritime Economics \& Logistics, 19, 538-550. https://doi.org/10.1057/mel.2016.1

[10] Makridakis, S. (1989) Management in the 21st Century. Long Range Planning, 22, 37-53. https://doi.org/10.1016/0024-6301(89)90122-2

[11] Faggini, M. and Parziale, A. (2012) The Failure of Economic Theory: Lessons from 
Chaos Theory. This Journal, 3, 1.

[12] Weatherall, J.O. (2013) The Physics of Wall Street: A Brief History of Predicting the Unpredictable. Houghton Mifflin Harcourt, 158.

[13] Buchanan, M. (2013) Forecast: What Physics, Meteorology, and the Natural Sciences Can Teach Us about Economics. Bloomsbury.

[14] Wolf, M. (2014) The Shifts and the Shocks: What We've Learned and Have Sill to Learn-From Financial Crisis. Penguin Press, New York.

[15] Priesmeyer, R.H. (1992) Organizations and Chaos: Defining the Methods of Nonlinear Management. Quorum Books, 173.

[16] Keynes, J.M. (1936) The General Theory of Employment Interest and Money. Macmillan \& Co. Ltd., 1961 Reprint.

[17] Bagehot, W. (1873) Lombard Street: A Description of the Money Market. http://www.gutenberg.org/ebooks/4359

[18] Minsky, H.P. (1982) Inflation, Recession, and Economic Policy. Brighton, Wheatsheaf.

[19] Blaug, M. (1997) Economic Theory in Retrospect. 5th Edition, Cambridge University Press.

[20] Kalecki, M. (1942) A Theory of Profits. Economic Journal, 52. https://doi.org/10.2307/2225784

[21] Soros, G. (2008) The New Paradigm for Financial Markets. Greek Translation in 2008 from Livanis Publishing House, Athens.

[22] Soros, G. (1998) The Crisis of Global Capitalism: The Open Society in Danger. Greek Translation in 1999 from Livanis Publishing House, Athens.

[23] Goulielmos, A.M. (2017) The "Kondratieff Cycles" in Shipping Economy since 1741 and till 2016. This Journal, 8, 308-332.

[24] Harrod, R.F. (1939) An Essay in Dynamic Theory. Economic Journal, 49, 14-33.

[25] Domar, E. (1946) Capital Expansion, Rate of Growth and Employment. Econometrica, 14, 137-147.

[26] Marshall, A. (1920) Principles of Economics: An Introductory. 8th Edition, Macmillan \& Co. Ltd., London.

[27] Pearce, D.W. (1992) Modern Economics, Macmillan Dictionary of. 4th Edition.

[28] Peters, E.E. (1994) Fractal Market Analysis: Applying Chaos Theory to Investment and Economics. John Wiley \& Sons, Inc.

[29] Granger, C.W.J. (1964) Spectral Analysis of Economic Time Series. Princeton University Press.

[30] Einstein, A. (1905) With Reference to the Required Movement of Small Particles Floating in a Stagnant Liquid in Accordance with the Molecule-Kinetic Theory of Heat. Title Translated by the Author. Annals of Physics, 322.

[31] Hurst, H.E. (1951) The Long-Term Storage Capacity of Reservoirs. Transactions of the American Society of Civil Engineers, 116.

[32] Steeb, W.-H. (2008)The Nonlinear Workbook. 4th Edition, World Scientific, Singapore. https://doi.org/10.1142/6883

[33] Regnault, J. (1863) Calculation of Chance and the Philosophy of Paris Stock Exchange. Mallet-Bachelier, Paris.

[34] Taqqu, M.S. (2001) Bachelier and His Times: A Conversation with Bernard Bru. Finance and Stochastics, 5, 3-32. https://doi.org/10.1007/PL00000039

[35] NLTSA by Syriopoulos, K. and Leontitsis, A. (2000) V.2.0 Nonlinear Time Series 
Analysis. Chaos: Analysis and Prediction of Time Series: With Applications to Athens Stock Exchange and Simple Examples. Anikoula Publications, Thessalonica. (In Greek)

[36] Lo, A.W. (1991) Long-Term Memory in Stock Market Prices. Econometrica, 59, 1279-1313. https://doi.org/10.2307/2938368

[37] Goulielmos, A.M. and Psifia, M.-E. (2011) Forecasting Short Term Freight Rate Cycles: Do We Have a More Appropriate Method than Normal Distribution? Maritime Policy \& Management, 38, 645-672. https://doi.org/10.1080/03088839.2011.556673

[38] Campbell, J.Y., Lo, A.W. and MacKinlay, A.C. (1997) The Econometrics of Financial Markets. Princeton University Press, New York.

[39] Ramsey, J.B. (1969) Tests for Specification Errors in Classical Linear Least-Squares Regression Analysis. Journal of Royal Statistical Society B, 31, 350-371.

[40] Brooks, C. (2014) Introductory Econometrics for Finance. 3rd Edition, Cambridge University Press.

[41] Jing, L., Marlow, P. and Hui, W. (2008) An Analysis of Freight Rate Volatility in Dry Bulk Shipping Markets. Maritime Policy \& Management, 35, 237-251. https://doi.org/10.1080/03088830802079987

[42] Bera, A.K. and Jarque, C.M. (1982) Model Specification Tests: A Simultaneous Approach. Journal of Econometrics, 20, 59-82. https://doi.org/10.1016/0304-4076(82)90103-8

[43] Syriopoulos, K. (1998) Analysis and Tests of One-Variable Finance Time Series. 2nd Edition, Athens. (In Greek)

[44] BDS by Brock, W.A., Dechert, D., Scheikman, H. and LeBaron, B. (1996) A Test for Independence Based on the Correlation Dimension. Econometric Reviews, 15, 197-235. https://doi.org/10.1080/07474939608800353

[45] Kanzler, L. (1999) Very Fast and Correctly Sized Estimation of the BDS Statistic. University of Oxford.

[46] Fama, E.F. (1965) The Behavior of Stock Market Prices. Journal of Business, 38, 34-104. https://doi.org/10.1086/294743

[47] Goulielmos, A.M. and Psifia, M.-E. (2009) Forecasting Weekly Freight Rates for One Year TC 65,000 Dwt BULK Carrier, 1989-2008, Using Nonlinear Methods. Maritime Policy \& Management, 36, 411-436. https://doi.org/10.1080/03088830903187150

[48] Farmer, D.J. and Sidorowich, J.J. (1987) Predicting Chaotic Time Series. Physical Review Letters, 59, 845-848. https://doi.org/10.1103/PhysRevLett.59.845

[49] Sauer, T. (1993) Time Series Prediction by Using Delay Coordinate Embedding. Addison-Wesley, 175-194.

[50] Casdagli, M (1991) Nonlinear Prediction of Chaotic Time Series. Physica D, 35, 335-356. https://doi.org/10.1016/0167-2789(89)90074-2

[51] Sugihara, G. and May, R. (1990) Nonlinear Forecasting as a Way of Distinguishing Chaos from Measurement Error in Time Series. Nature, 344, 734-740. https://doi.org/10.1038/344734a0

[52] Kugiumtzis, D., Lingjaerde, O.C. and Christophersen, N. (1998) Regularized Local Linear Prediction of Chaotic Time Series. Physica D, 112, 344-360. https://doi.org/10.1016/S0167-2789(97)00171-1 